\title{
Correction to: Comparison of the efficiency, safety, and survival outcomes in two stem cell mobilization regimens with cyclophosphamide plus G-CSF or G-CSF alone in multiple myeloma: a meta-analysis
}

\author{
Liwen Wang ${ }^{1,2} \cdot$ Hongxian Xiang ${ }^{1,2} \cdot$ Yuhan Yan ${ }^{1,2} \cdot$ Zuqun Deng ${ }^{1,2} \cdot \mathrm{Hui} \mathrm{Li}^{3} \cdot{\mathrm{Xin} \mathrm{Li}^{1} \cdot \text { Jing Liu }}^{1}$ \\ Published online: 18 January 2021 \\ (C) Springer-Verlag GmbH Germany, part of Springer Nature 2021
}

\section{Correction to: Annals of Hematology}

https://doi.org/10.1007/s00277-020-04376-w

In the above-mentioned article, the name of one author Jin Liu was misspelled unintentionally. For this author, the name should be corrected as follows: Jing Liu.

Publisher's note Springer Nature remains neutral with regard to jurisdictional claims in published maps and institutional affiliations.

The online version of the original article can be found at https://doi.org/ $10.1007 / \mathrm{s} 00277-020-04376-\mathrm{w}$

Jing Liu

lj0jingliu@163.com

1 Department of Hematology, Third Xiangya Hospital, Central South University, Changsha 410013, Hunan Province, China

2 Xiangya School of Medicine, Central South University, Changsha 410013, Hunan Province, China

3 Assisted Reproduction Unit, Department of Obstetrics and Gynecology, Sir Run Shaw Hospital, School of Medicine, Zhejiang University, Province, Zhejiang 310016, Hangzhou, China 